SESSION III. DEVELOPMENTS AND FUTURE ASPECTS

Chairman: ENNO FREERKSEN (FRG) 


\section{Recent developments in the field of multidrug therapy and future research in chemotherapy of leprosy}

\section{J H GROSSET}

Laboratoire de Bactériologie, Faculté de Médecine Pitié-Salpêtrière, 75634 Paris Cedex 13, France

The discovery of rifampicin in the late sixties together with the increasing prevalence of dapsone resistance were decisive factors in questioning the value of the traditional dapsone monotherapy for the treatment of leprosy. As rifampicin demonstrated a strong bactericidal activity against Mycobacterium leprae, it became an obligatory component of the treatment of leprosy during the decade 1970-1980, at least when its cost was not prohibitive. Then it was progressively understood that leprosy, a mycobacterial disease with a large bacillary population like tuberculosis, had to be treated like tuberculosis with a combination of drugs. ${ }^{1-4}$ Actually to be a success, chemotherapy for leprosy as well as for tuberculosis should be capable of preventing the selection of drug-resistant organisms (mutants) and killing as many as possible of the drug-sensitive organisms. ${ }^{5}$ When the selection of drug-resistant mutants is prevented, no failures during chemotherapy and no relapses after stopping chemotherapy due to acquired drug resistance will occur. When all or nearly all drug-sensitive organisms are killed, no relapse or a limited number of relapses with sensitive organisms will occur after stopping chemotherapy.

The aim of this paper is to summarize what is known about the microbial population present in multibacillary cases of leprosy and the response of these microbial populations to the drugs administered during the course of chemotherapy. Finally a series of leads for future research in chemotherapy of leprosy will be proposed.

\section{The microbial population in multibacillary leprosy}

It is assumed ${ }^{6}$ that the maximum number of acid-fast bacilli (AFB) in the majority of multibacillary cases of leprosy is not more than $10^{11}$, i.e. 11 decimal logarithms $(\log )$ AFB. This assumption fits well with the calculations made from the number of AFB in the biopsies taken from multibacillary cases of leprosy. As shown in 
Table 1, among 320 biopsies received in our laboratory for mouse inoculation from January 1980 to December 1985, 75\% contained between 5 and $7 \log$ AFB per $\mathrm{mg}$ of tissue, that is $8-10 \log$ per gram, which means approximately $10-12 \mathrm{log}$ bacilli per patient. Among the total $11 \log$ AFB that are present before the start of chemotherapy as few as $1-5 \%$ are capable of growing in the footpad of mice and thus are considered viable. Therefore, the mean size of the viable bacillary population of a patient with multibacillary leprosy may be estimated to be about $9 \log$.

From the chemotherapeutic point of view the viable bacillary population is composed of various subpopulations, a large one of drug-sensitive organisms and small populations of drug-resistant organisms, each of them consisting of mutants resistant to one definite drug. By analogy with what is known about $M$. tuberculosis ${ }^{7-10}$ and only by analogy because no direct evidence is available for the time being about $M$. leprae, one may estimate the mean proportion of resistant mutants within a wild strain of $M$. leprae to be $10^{-7}(-7 \log )$ for rifampicin (RMP) and $-6 \log$ for dapsone (DDS), clofazimine (CLO) or a thionamide (TH), ethionamide (ETH), or prothionamide (PTH). Thus besides the 9 log subpopulation of organisms sensitive to all drugs, there should be a small subpopulation of 2 $\log$ RMP-resistant mutants and several subpopulations of $3 \log$ DDS, CLO and TH resistant mutants (Figure 1).

The outcome of the different subpopulations differs according to the type of chemotherapy prescribed. If monotherapy (for example dapsone or rifampicin alone) is prescribed to treat a lepromatous patient the drug-sensitive organisms will be progressively eliminated whereas the subpopulation of mutants resistant to the prescribed drug will survive, be selected and be responsible for late relapses with drug-resistant organisms. If multidrug therapy is prescribed, there will be no survival and therefore no selection of drug-resistant mutants because each drug will be active against the mutants resistant to the other drugs. However, to ascertain that no drug-resistant mutants will be selected multidrug therapy should be given until all drug-resistant mutants present at the start of treatment are killed. Moreover, as new drug-resistant mutants can arise from the 9 log sensitive subpopulation, multidrug therapy should be given until this subpopulation is reduced below $6 \mathrm{log}$, a level under which the probability for a new drugresistant mutant to occur is extremely low. In summary, to prevent the selection of drug-resistant mutants (in other words, to prevent acquired drug resistance), multidrug therapy should be given as long as drug-resistant mutants present at the start of therapy are not killed and as long as the size of the sensitive bacillary population is not strongly reduced. These are the two objectives of the initial phase of multidrug therapy (Figure 1), the duration of which is still unknown as we will see later on.

Then it remains to take care of the relatively limited number of sensitive organisms that have survived the initial phase of chemotherapy. At this stage there is no longer a risk of selecting drug-resistant mutants, thus combined 


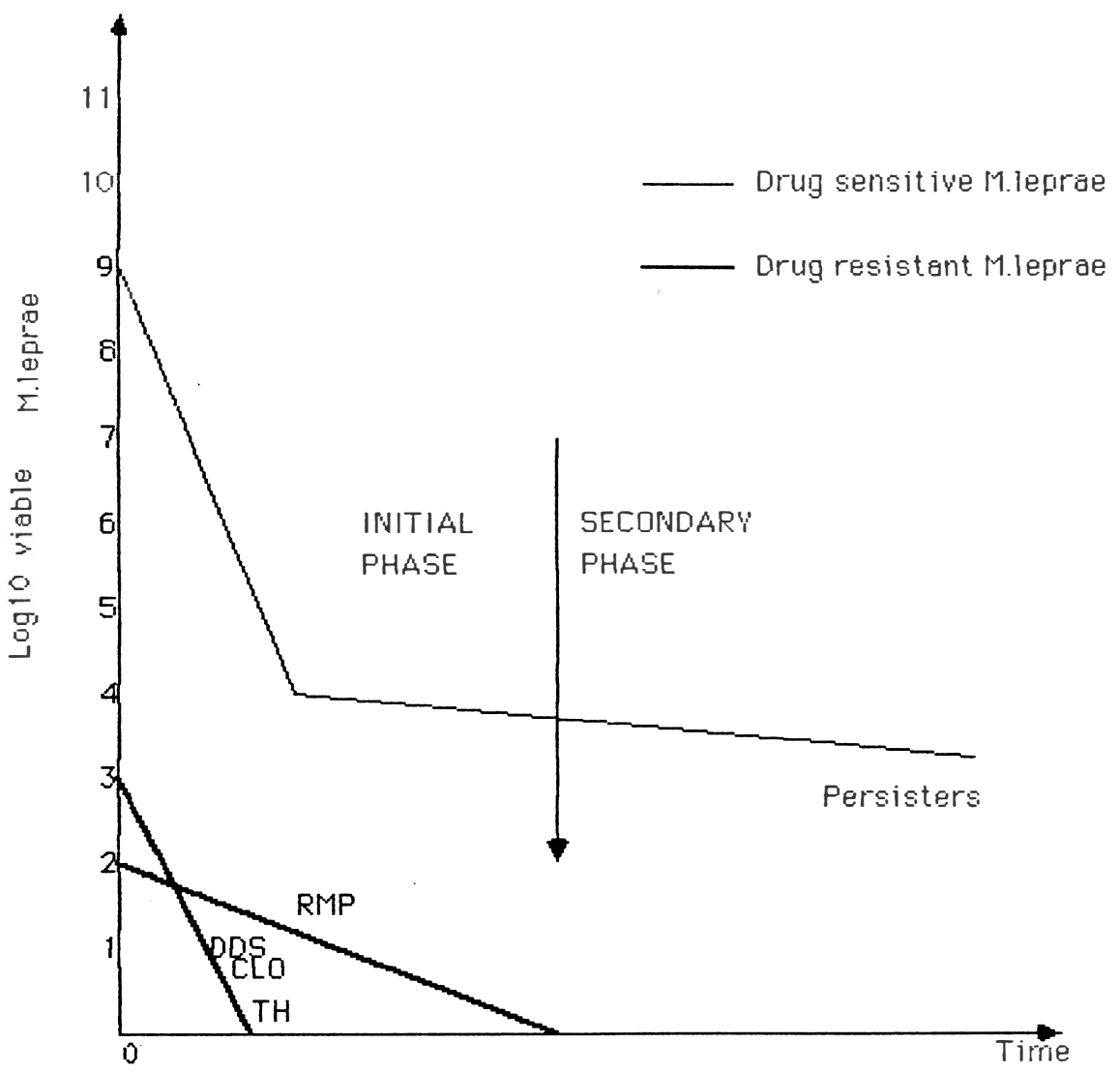

Figure 1. The outcome of $M$. leprae subpopulations during multidrug chemotherapy of multibacillary leprosy. (RMP, rifampicin; DDS, dapsone; CLO, clofazimine; TH, thionamide).

chemotherapy is no longer required. Drug therapy should be used to kill the remaining organisms, or at least to keep them in a dormant state so that the clearing mechanisms of the host can eliminate them progressively. If multidrug therapy is given at this stage it is because the combination of drugs has demonstrated (or is thought to have) a synergistic activity against $M$. leprae. One important question concerning the secondary phase of chemotherapy is to know how long this secondary phase should be continued? The evident answer is until a period of time such that there will be no relapse at all or an acceptable proportion of relapses $(\leq 5 \%)$ after stopping treatment.

Therefore, it is important to examine successively what is known about the initial phase and the secondary phase of chemotherapy and in which directions the future investigations in leprosy chemotherapy should go. 


\section{The initial phase of chemotherapy for leprosy}

At present, a number of data ${ }^{1-14}$ are available about the initial phase of chemotherapy for leprosy with rifampicin. First of all it was demonstrated that biopsies taken from patients having received a single dose of $600 \mathrm{mg}$ rifampicin failed usually to give growth of $M$. leprae in the footpad of mice, whereas it took 3-6 months of daily treatment to obtain the same results with either dapsone alone, or clofazimine or ethionamide. ${ }^{15-18}$ The extremely rapid initial killing of $M$. leprae by rifampicin has been measured in the recent Bamako-Chingleput study ${ }^{19}$ carried out within the THELEP activities. After three months of chemotherapy with either daily $600 \mathrm{mg}$ rifampicin, $100 \mathrm{mg}$ dapsone and $100 \mathrm{mg}$ clofazimine or

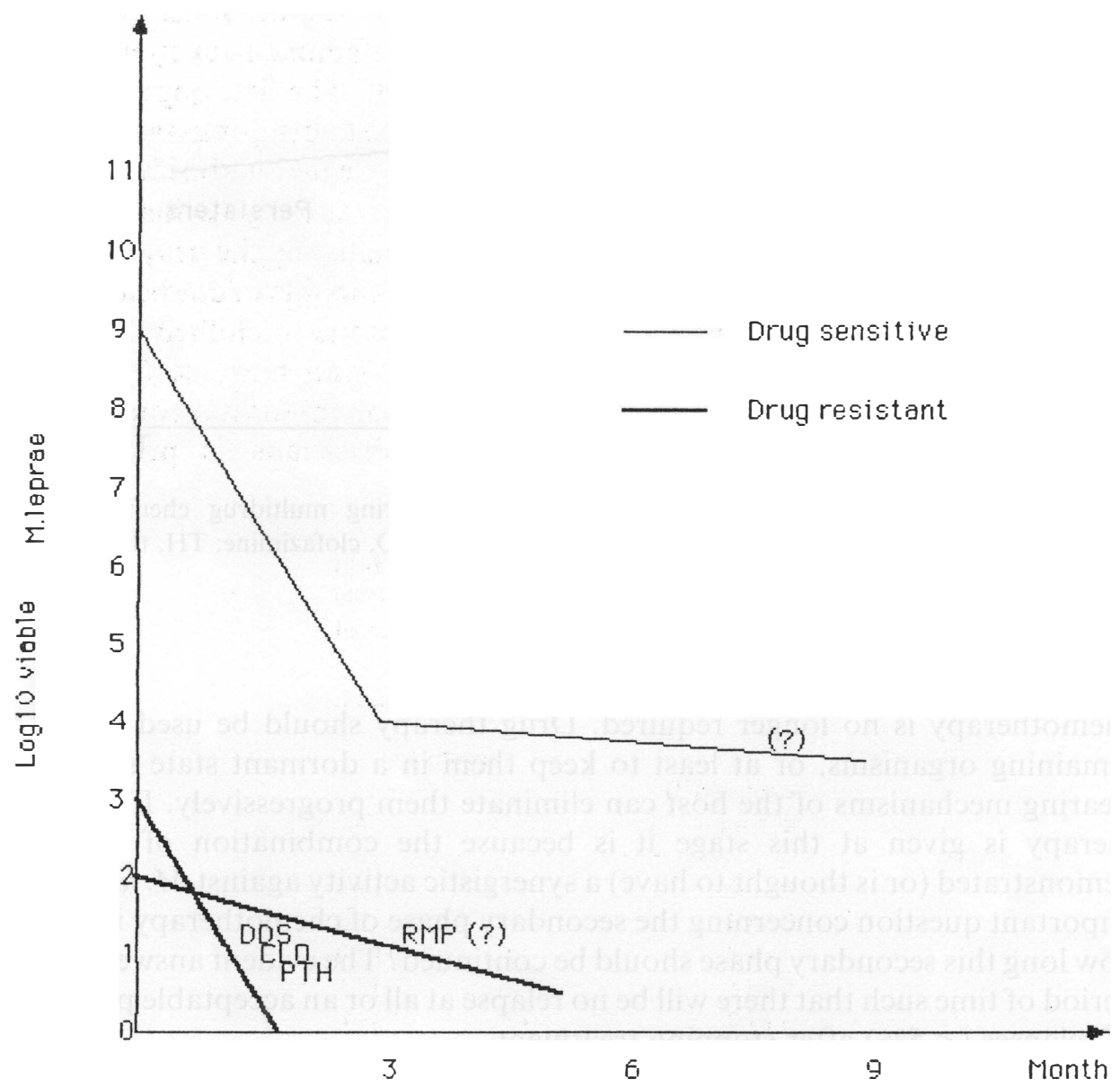

Figure 2. Known and unknown data on the outcome of $M$. leprae subpopulations under combined chemotherapy with rif ampicin. 
weekly $600 \mathrm{mg}$ rifampicin plus daily dapsone and clofazimine or daily dapsone supplemented by an initial single dose of $1500 \mathrm{mg}$ rifampicin, the proportion of AFB capable of multiplying in the hind footpad of thymectomized-irradiated (TR) mice was in the range of $-7 \mathrm{log}$. Because the proportion of AFB that were able to grow in mice were not different among patients in the $3 \mathrm{rd}$ month of chemotherapy who received daily $600 \mathrm{mg}$ rifampicin and patients who received only a single initial dose of $1500 \mathrm{mg}$ rifampicin, one is led to assume that the initial killing resulted mainly from the first dose of rif ampicin. If $1 \%$ of the 11-log AFB present at the start of treatment were viable, then a few days after the start of chemotherapy rifampicin should have killed $5 \log$ of the rifampicin sensitive $M$. leprae. These include not only the majority of the largest subpopulation of fully sensitive bacilli but also all of the two 3-log subpopulations of dapsone- and clofazimine-resistant mutants which are by definition susceptible to rifampicin.

After the initial dose of rifampicin the only surviving organisms should be about $4 \log$ rif ampicin-sensitive bacilli and the $2 \log$ rif ampicin-resistant mutants that were already present before beginning treatment. The first population of 4 log rif ampicin-sensitive bacilli is too limited to give rise to drug-resistant mutants. Therefore, when multibacillary cases of leprosy are treated with rifampicin the only risk of acquired resistance comes from the subpopulation of $2 \log$ rif ampicin-resistant mutants. These have to be eliminated by the drug(s) given in combination. In theory only, a single drug should be capable of eradicating these 2 log rifampicin-resistant mutants, for example dapsone or clofazimine. But in practice it is safer to give two drugs for the following reasons: (i) the high prevalence of primary and acquired dapsone resistance; (ii) the noncompliance of patients to take the prescribed drugs and of physicians to prescribe the

Table 1. Number of acid-fast bacilli in biopsies received in Paris between 1980 and 1985 from multibacillary cases of leprosy

\begin{tabular}{|c|c|c|}
\hline \multirow{2}{*}{$\begin{array}{l}\log _{10} \mathrm{AFB} \\
\text { per mg }\end{array}$} & \multicolumn{2}{|c|}{ Biopsies } \\
\hline & $\mathbf{N}^{\circ}$ & $\%$ \\
\hline less than 3 & 34 & $10 \cdot 6$ \\
\hline 3 to 4 & 5 & 1.5 \\
\hline 4 to 5 & 38 & 11.9 \\
\hline 5 to 6 & 125 & $39 \cdot 1$ \\
\hline 6 to 7 & 117 & $36 \cdot 6$ \\
\hline 7 and more & 1 & $0 \cdot 3$ \\
\hline Total & 320 & 100 \\
\hline
\end{tabular}


recommended regimens; and (iii) the relatively low killing activity of drugs other than rifampicin. Although the first two reasons are of utmost importance we are not going to concentrate on them. It is enough to say that it is not safe to rely entirely on dapsone alone to kill the RMP resistant mutants, especially in previously dapsone treated patients. Rather, dapsone should be given with another drug, either a thionamide or clofazimine, or both. In field practice many people are now reluctant to use a thionamide at least in some areas because of its liver toxicity, especially in combination with rifampicin. ${ }^{20-23}$ Thus one should mainly rely upon the combination dapsone-clofazimine to get rid of the RMPresistant mutants.

One can wonder whether all of the above reasoning is based upon theoretical speculation or realistic assumptions. Actually, if we consider (Table 2) the results of drug sensitivity testing of $M$. leprae isolated in our laboratory between 1980 and 1984 it is clear that the risk of drug resistance is a reality. Biopsies of 69 patients mainly from Caribbean Islands (Martinique, Guadeloupe), Paris (France) and New Caledonia who had been previously treated for years with a single drug (some patients had been treated successively by dapsone alone and af ter a first relapse by rifampicin alone) yielded in 35 cases strains fully resistant to dapsone and in 13 cases strains resistant to rifampicin. Although these strains came from places where an intensive use of antileprosy drugs took place and were not representative worldwide, they demonstrate, with numerous other studies, ${ }^{24,25}$ the reality of the drug-resistance threat. Other data which could be important for the future of leprosy control are the incidence of primary dapsone resistance. Among the 70 strains of $M$. leprae isolated from untreated patients 47 were resistant to dapsone, the majority of them of low level dapsone resistance. Although such a low level dapsone resistance is of limited clinical significance it may be considered as a first step towards a higher and more significant dapsone resistance.

Table 2. Drug resistance of $M$. leprae isolated in Paris from 1980 to 84

\begin{tabular}{|c|c|c|c|c|c|c|c|}
\hline \multicolumn{2}{|c|}{ Strains of $M$. leprae } & \multicolumn{4}{|c|}{$\begin{array}{l}\text { Susceptibility to dapsone } \\
\text { resistant* to }\end{array}$} & \multicolumn{2}{|c|}{$\begin{array}{l}\text { Susceptibility to } \\
\text { rifampicin } \dagger\end{array}$} \\
\hline isolated from & $\mathrm{N}^{\circ}$ & $\mathrm{S}$ & $0 \cdot 0001$ & $0 \cdot 001$ & $0 \cdot 01$ & S & $\mathrm{R}$ \\
\hline $\begin{array}{l}\text { Previously treated } \\
\text { patients }\end{array}$ & 69 & 7 & 6 & 21 & 35 & 56 & 13 \\
\hline $\begin{array}{l}\text { Untreated } \\
\text { patients }\end{array}$ & 70 & 23 & 34 & 7 & 6 & 70 & 0 \\
\hline
\end{tabular}


As far as we know at present one might and one should rely upon the combination dapsone-clofazimine to get rid of the RMP-resistant mutants. Then one should prescribe this combination as long as all rifampicin-resistant mutants have not been eliminated. But we do not know exactly how long the treatment with the combination dapsone-clofazimine should last to kill the 2-log population of rifampicin resistant mutants. We do know from numerous studies ${ }^{17,18}$ that AFB from previously untreated patients who are treated with dapsone or clofazimine alone fail to grow in the normal mouse after 3-6 months of treatment and that the addition of clofazimine to dapsone increases the effectiveness of treatment. If we are optimistic we might expect the same thing to occur in patients treated with the combination rif ampicin, dapsone and clofazimine, and the initial phase of chemotherapy to be capable of eliminating all drug-resistant mutants within 6 months. However if we are pessimistic we might expect rifampicin to induce a generalized state of persistence among all viable organisms that have not been killed by the initial dose of the drug. If the organisms are rendered unresponsive to rifampicin because of their metabolic inactivity they should be similarly unresponsive to the other drugs. Thus the rifampicin-resistant mutants are likely to respond badly to the combination dapsone--clofazimine. In this event the combination dapsone-clofazimine would take longer than 6 months and perhaps the whole course of chemotherapy to get rid of the RMP resistant mutants. It is, therefore, a priority to determine with precision the length of time required by the combination dapsone-clofazimine to obtain a $2-3 \log$ decrease in the RMP-resistant population. This period should thus be the length of time of the initial phase of chemotherapy. As long as we do not have this information, and in order to remain on the safe side, it is highly recommended to give the combination dapsone-clofazimine during the whole course of chemotherapy.

\section{The secondary phase of chemotherapy}

The initial phase of chemotherapy having eliminated all drug-resistant mutants and reduced the size of the viable drug-sensitive population to $4 \log$ bacilli, the secondary phase is responsible for the elimination of the remaining bacilli. But in the Bamako-Chingleput study to which reference was made above, ${ }^{19}$ the proportion of AFB capable of multiplying in mice remained constant during the 2 years of treatment, indicating that chemotherapy was, after the initial rapid killing of $M$. leprae apparently ineffective against the remaining $M$. leprae. These $M$. leprae were not drug-resistant organisms selected by the chemotherapy because the few bacilli that grew in the footpad of mice were normally sensitive to rifampicin and other drugs. They behaved as true persisters, that is organisms unresponsive to the drugs to which they are fully susceptible. ${ }^{26,27}$ Such persisters have also been observed in leprosy after long-term dapsone therapy and in many other infectious diseases including tuberculosis. ${ }^{28-30}$ 
Faced with the apparent unresponsiveness of $M$. leprae persisters to chemotherapy, the obvious question is whether or not we should try to get rid of the 4-log persisters because they are potentially responsible for relapses after stopping treatment. In other words should chemotherapy be continued or stopped after all drug-resistant mutants have been killed? At a time when we do not know how long it takes to kill all drug-resistant mutants, we are still more ignorant about the optimal length of the continuation phase of chemotherapy. However one tentative answer to the question of the length of the continuation phase can be brought by the results of the Bamako-Chingleput study. In this study, the load of AFB in the serial skin smears decreased by 0.62 log per year. Because the proportion of persisters among AFB remained constant $(-7 \log )$ during the 2 years of the study, it is possible to infer that the clearing of persisters was parallel to the clearing of the AFB in the skin smears and was also of 0.62 log per year. If that is right it is possible to calculate the length of time needed to clear 4 - log persisters. This length of time is 4 divided by 0.62 , that is 6.45 years or more simply 7 years for multibacillary cases of leprosy with maximum bacterial load, that is more or less the time needed to reach skin smear negativity. For multibacillary cases of leprosy with lower bacterial load, the length of chemotherapy would depend upon the initial load of AFB and the speed of its decrease under chemotherapy. For the previously treated patients with already negative or poorly positive skin smears, the optimal length of combined chemotherapy could well be still shorter.

To validate this reasoning, it is interesting to compare the calculated length of time needed for the chemotherapy of leprosy with rifampicin to get rid of persisters with the known length of time needed for the short-course chemotherapy of tuberculosis to be fully effective (to prevent relapses in almost $100 \%$ of the cases). Four-drug chemotherapy of tuberculosis with isoniazid, rifampicin, pyrazinamide and streptomycin (or ethambutol) should last 6 months to be followed by an acceptable relapse rate. Let us consider that the mean division time is about one day for $M$. tuberculosis (actually $20 \mathrm{hr}$ ) and about 14 days for $M$. leprae (actually between 12 and 20 days), i.e. 14 times longer. If the clearing of persisters under chemotherapy is related to the division time of the mycobacterial species, then one may calculate from the time needed to eliminate persisters under short-course chemotherapy of tuberculosis that the length of time needed to eliminate persisters under multidrug chemotherapy of leprosy is 6 months $\times 14=84$ months or 7 years! This figure fits surprisingly well with the figure estimated from the Bamako-Chingleput study.

Finally it should be emphasized that the preceding reasoning is purely speculative and perhaps far too pessimistic. Because standard regimens of combined chemotherapy have been introduced very recently, nobody knows exactly the importance of the threat represented by the $M$. leprae that persist despite combined chemotherapy with rifampicin or even whether these persisters are actually threatening the future of multibacillary patients after stopping 
treatment. Only carefully-designed long-term studies in the next 10 years will provide answers to the questions concerning the optimal length of chemotherapy for leprosy.

\section{Future research in chemotherapy of leprosy}

In the last decade tremendous advances were made in the chemotherapy of leprosy. At present it is generally agreed that: (i) rifampicin should as far as possible be a component of all antileprosy regimens; (ii) rifampicin should be combined with at least one and preferably two active drugs to prevent the selection of rif ampicin-resistant mutants; and (iii) due to the high killing activity of rifampicin, the treatment of even the most severe lepromatous cases of leprosy does not need to be lifelong. Although there is ample indirect evidence that multidrug therapy of leprosy with rifampicin is necessary and will improve to a large extent the results of chemotherapy for leprosy control programmes, it should be realized that direct evidence will be obtained only in the range of the next 10 years. An obvious reason for this delay is the long division time of $M$. leprae (about 14 days) which seems also to be responsible for the slow evolution of the disease and for the slow motion of all events in leprosy. Another reason which is not always well understood is the limited precision of the tools (skin smear, mouse inoculation, phenolic glycolipid serology) available to assess success and failures in the chemotherapy of leprosy. Improvement in the sensitivity of the available tools and discovery of new tools to assess the response of patients to chemotherapy are therefore needed.

A number of questions, that deserve perhaps to be thought about, may be raised about the response of $M$. leprae to chemotherapy. For example one can wonder whether the rapid initial killing of $M$. leprae by rifampicin is due to the poor viability of the microbial cells at the beginning of treatment or to the special susceptibility of the target of rif ampicin, the RNA polymerase of $M$. leprae. It is striking that one single dose of $1500 \mathrm{mg}$ rifampicin combined with daily dapsone is capable of killing $5 \log M$. leprae in a few days whereas it takes at least 2 months of daily treatment with the combination of three bactericidal drugs, namely rifampicin, isoniazid and pyrazinamide, to kill $5 \log M$. tuberculosis. ${ }^{5}$ If the $M$. leprae RNA polymerase was actually different from that of $M$. tuberculosis and other bacteria ${ }^{31}$ that would explain why the effectiveness of rifampicin against all of the bacterial species except $M$. leprae decreases when the interval between each individual $10 \mathrm{mg} / \mathrm{kg}$ dose increases. ${ }^{32}$

Another striking finding of the Bamako-Chingleput study is the apparent unresponsiveness of $M$. leprae to rifampicin during treatment after the initial dramatic response. This secondary unresponsiveness might well be the result of some special interaction between the host macrophage and $M$. leprae or of the chemical structure of $M$. leprae RNA polymerase or both. If the first hypothesis 
was right, then it should perhaps be possible to improve the response of $M$. leprae persisters to rifampicin by combining immunotherapy and chemotherapy. Such an hypothesis is certainly worth testing experimentally and clinically. If the second hypothesis was right, then the identification of the $M$. leprae RNA polymerase could be of utmost importance to understand the mechanisms of action of rifampicin against $M$. leprae and to improve the effectiveness of multidrug therapy.

Among other directions for future research, the relationship between the presence of persisters and the risk of relapse after stopping treatment is certainly one that deserves high priority. M. leprae persisters have been isolated after a long course of dapsone monotherapy ${ }^{30}$ as they have been isolated after a long course of multidrug therapy. ${ }^{26,27,33}$ But we do not know whether the size of the persisters population is similar after dapsone monotherapy and after multidrug therapy. Similarly, we do not know whether there is a relation between the size of the persisters population, the risk of relapse and the length of time that elapses between the end of chemotherapy and the relapse. To answer these questions experimental and clinical investigations are certainly needed. But it should be recognized that they will be difficult and costly to perform.

It should be recalled that at present only four drugs, namely rifampicin, the thionamides, dapsone and clofazimine, are active against $M$. leprae and only rifampicin has a strong bactericidal activity. Therefore chemotherapy of leprosy needs new compounds with a bactericidal activity to back up rifampicin and to overcome the increasing prevalence of dapsone resistance. ${ }^{25}$ Among new compounds active against $M$. leprae only the new fluoroquinolones appear promising. ${ }^{34}$ Their activities in the mouse and even in man are still under study but the initial results are favourable. Finally one can hope that fundamental research involving all new tools used in molecular biology will permit us not only an understanding of the mechanisms of action of the already known antileprosy drugs, and to improve their use, but also to discover new leads.

\section{References}

${ }^{1}$ Fifth Report of the WHO Expert Committee on Leprosy. WHO Tech. Rep. Ser., No. 607, 1977.

${ }^{2}$ Freerksen E, Rosenfeld M. Leprosy Eradication project of Malta. 1st published report after 5 years running. Chemotherapy, 1977; 23: 356-386.

${ }^{3}$ Freerksen E, Rosenfeld M, Bonnici E, De Pasquale G, Kruger-Thiemer M. Combined chemotherapy in leprosy, background and findings. Chemotherapy, 1978; 24: 187-201.

${ }^{4}$ Report of a WHO Study Group. Chemotherapy of leprosy for control programmes. WHO Tech. Rep. Ser., No. 675, 1982.

${ }^{5}$ Grosset JH. Bacteriologic basis of short-course chemotherapy for tuberculosis. Clinics in Chest Medicine, 1981; 1: 231-241.

${ }^{6}$ Shepard CC. Recent developments in the chemotherapy and chemoprophylaxis of leprosy. Leprologia (Argentina), 1974, 19: 230-236. 
7 Canetti G, Grosset J. Teneur des souches sauvages de $M$. tuberculosis en variants résistants à l'isoniazide et en variants résistants à la streptomycine sur milieu de Lowenstein-Jensen. Ann Inst Pasteur, 1961; 101: 28-46.

${ }^{8}$ Grosset J, Canetti G. Teneur des souches sauvages de $M$. tuberculosis en variants résistants aux antibiotiques mineurs (acide para-amino-salicylique, éthionamide, cycloserine, viomycine, kanamycine). Ann Inst Pasteur, 1962; 103: 163-184.

${ }^{9}$ Canetti G, Rist N, Grosset J. Mesure de la sensibilité du bacille tuberculeux aux drogues antibacillaires par la méthode des proportions. Rev Tuberc Pneum, 1963; 27: 217-272.

10 Le Lirzin M, Djurovic V. Etude sur milieu de Loewenstein-Jensen de la composition des souches sauvages de Mycobacterium tuberculosis en variants résistant à la rifampicine et en variants résistant à l'éthambutol. Ann Inst Pasteur, 1971; 120: 531-548.

11 Shepard CC, Levy L, Fasal P. Rapid bactericidal effect of rifampicin on Mycobacterium leprae. Amer J Trop Med Hyg, 1972; 21: 446-9.

12 Shepard CC, Levy L, Fasal P. Further experience with the rapid bactericidal effect of rifampin on Mycobacterium leprae. Amer J Trop Med Hyg, 1974; 23: 1120-4.

13 Collaborative effort of the US Leprosy Panel (US-Japan Cooperative Medical Science Program) and the Leonard Wood Memorial. Rifampin therapy of lepromatous leprosy. Amer J Trop Med Hyg, 1975; 24: 475-84.

${ }^{14}$ Levy L, Shepard CC, Fasal P. The bactericidal effect of rifampicin on $M$. leprae in man: a) single doses of 600, 900 and $1200 \mathrm{mg}$; and b) daily doses of $300 \mathrm{mg}$. Int J Lepr, 1976; 44: 183-7.

15 Waters MFR, Rees RJW. Changes in the morphology of Mycobacterium leprae in patients under treatment. Int J Lepr, 1962; 30: 266-77.

16 Waters MFR, Pettit JHS. Chemotherapeutic trials in leprosy. 2. Comparative trial of dapsone plus ditophal (etisul) and dapsone alone in the treatment of lepromatous leprosy. Int J Lepr, 1965; 33: 280-96.

17 Shepard CC, Levy L, Fasal P. The death of Mycobacterium leprae during treatment with 4,4'diaminodiphenylsulfone (DDS). Amer J Trop Med Hyg, 1968; 17: 769-75.

18 Levy L, Shepard CC, Fasal P. Clofazimine therapy of lepromatous leprosy caused by dapsoneresistant Mycobacterium leprae. Amer J Trop Med Hyg, 1972; 21: 315-21.

19 Subcommittee on Clinical Trials of the Chemotherapy of Leprosy (THELEP) Scientific Working Group of the UNDP/World Bank/WHO Special Programme for Research and Training in Tropical Diseases. THELEP controlled clinical trials in lepromatous leprosy. Lepr Rev, 1983; 54: $167-176$.

${ }^{20}$ Cartel JL, Millan J, Guelpa-Lauras CC, Grosset J. Hepatitis in leprosy patients treated by a daily combination of dapsone rifampin, and a thioamide. Int J Lepr, 1983; 51: 461-465.

${ }^{21}$ Pattyn SR, Janssens L, Bourland J, Saylan T, Davies EM, Grillone S, Ferraci C and the collaborative study group for the treatment of leprosy. Hepatotoxicity of the combination of rif ampin-ethionamide in the treatment of multibacillary leprosy. Int $J$ Lepr, 1984; 52: 1-6.

$22 \mathrm{Ji} \mathrm{B}$, Chen J, Wang C, Xia G. Hepatotoxicity of combined therapy with rifampicin and daily prothionamide for leprosy. Lepr Rev, 1984; 55: 283-289.

${ }^{23}$ Cartel JL, Naudillon Y, Artus JC, Grosset JH. Hepatotoxicity of the daily combination of $5 \mathrm{mg} /$ $\mathrm{kg}$ protionamide $+10 \mathrm{mg} / \mathrm{kg}$ rifampin. Int J Lepr, 1985; 53: 15-18.

${ }^{24}$ Pettit JHS, Rees RJW. Sulphone resistance in leprosy. An experimental and clinical study. Lancet, 1964; ii: 673-4.

25 Ji B. Drug resistance in leprosy - a review. Lepr Rev, 1985; 56: 265-278.

${ }^{26}$ Rees RJW, Waters MRF, Pearson JMH, Helmy HS, Laing ABG. Long-term treatment of dapsone-resistant leprosy with rifampicin: clinical and bacteriological studies. Int J Lepr 1976; 44: 159-69.

27 Gelber RH, Waters MFR, Pearson JMH, Rees RJW, McDougall AC. Dapsone alone compared with dapsone plus rifampicin in short-term therapy of lepromatous leprosy. Lepr Rev, 1977; 48: 223-9. 
${ }^{28}$ McDermott W. Microbial Persistence. Yale J Biol Med, 1958; 30: 257-329.

${ }^{29}$ Grosset J, Guelpa-Lauras CC, Lecoeur H, Truffot-Pernot Ch. Microbial Persistence in mycobacterial infections. Quaderni di Cooperazione sanitaria-Health Cooperation papers, 1983; 1: 41-49.

30 Waters MFR, Rees RJW, McDougall AC, Weddell AGM. Ten years of dapsone in lepromatous leprosy: clinical, bacteriological and histological assessment and the finding of viable leprosy bacilli. Lepr Rev, 1974; 45: 288-98.

31 Wehrli W. Rif ampin: mechanisms of action and resistance. Rev Inf Diseas, 1983; 5: S407-411.

32 Grosset J, Truffot-Pernot Ch, Bismuth R, Lecoeur H. Recent results of chemotherapy in experimental tuberculosis of the mouse. Bulletin Intern Union Against Tuberc, 1983; 58: 90-96.

33 Toman K. Bacterial Persistence in leprosy. Int J Lepr, 1981; 49: 205-17.

${ }^{34}$ Grosset J, Jarlier V, Truffot-Pernot Ch, Guelpa-Lauras CC, Lecoeur H. Activité des nouvelles quinolones sur les mycobactéries. In Les Nouvelles Quinolones, Arnette Edit. Paris, 1985: 181189. 